\title{
High outcrossing rates in fields with mixed sorghum landraces: how are landraces maintained?
}

\author{
A Barnaud ${ }^{1,3}$, G Trigueros ${ }^{1,3}$, D McKey ${ }^{2}$ and HI Joly ${ }^{1}$ \\ ${ }^{1}$ CIRAD, UMR 5175-CEFE (Centre d'Ecologie Fonctionnelle et Evolutive), Montpellier, France and 'Université Montpellier II, UMR \\ 5175-CEFE (Centre d'Ecologie Fonctionnelle et Evolutive), Montpellier, France
}

\begin{abstract}
The effect of mating system on genetic diversity is a major theme in plant evolutionary genetics, because gene flow plays a large role in structuring the genetic variability within and among populations. Understanding crop mating systems and their consequences for gene flow can aid in managing agricultural systems and conserving genetic resources. We evaluated the extent of pollen flow, its links with farming practices and its impact on the dynamics of diversity of sorghum in fields of Duupa farmers in Cameroon. Duupa farmers grow numerous landraces mixed in a field, a practice that favours extensive pollen flow. We estimated parameters of the mating system of five landraces representative of the genetic diversity cultivated in the study site, using a direct method based on progeny array. The multilocus outcrossing rate calculated from all progenies was $18 \%$ and ranged from 0 to $73 \%$ among progenies.
\end{abstract}

Outcrossing rates varied greatly among landraces, from 5 to $40 \%$. Our results also showed that individual maternal plants were usually pollinated by more than eight pollen donors, except for one landrace (three pollen donors). Although the biological traits of sorghum (inflorescence morphology, floral traits, phenology) and the spatial planting practices of Duupa farmers led to extensive pollen flow among landraces, selection exerted by farmers appears to be a key parameter affecting the fate of new genetic combinations from outcrossing events. Because both natural and human-mediated factors shape evolution in crop populations, understanding evolutionary processes and designing in situ conservation measures requires that biologists and anthropologists work together.

Heredity (2008) 101, 445-452; doi:10.1038/hdy.2008.77; published online 6 August 2008

Keywords: gene flow; mating system; conservation; sorghum; Duupa; Cameroon

\section{Introduction}

Domesticated plants exhibit a diversity of mating systems, ranging from obligatory outcrossing to selffertilization or even apomixis (Leblanc et al., 1995; RossIbarra et al., 2007). The effect of the mating system on genetic diversity is a major theme in plant evolutionary genetics, because gene flow plays a large role in structuring the genetic variability within and among populations. Understanding crop mating systems and their consequences for gene flow can contribute to the scientific basis for managing agricultural systems, conserving genetic resources and using these resources in breeding programs.

As a complement to experimental studies, it is necessary to document pollen flow in situ, because it can be modified by phenology, field size and planting practices. In traditional farming systems, biological and human factors interact to shape evolutionary forces (Jarvis and Hodgkin, 1999). Biological factors comprise both environmental pressures and biological traits of the plant, such as its mating system. Human factors affect the dynamics of diversity in many ways, acting on gene flow, drift and selection.

Correspondence: Dr A Barnaud, UMR 5175-CEFE, CIRAD, 1919 route de Mende, Montpellier 34293, France.

E-mail: adelinebarnaud@hotmail.com

${ }^{3}$ These authors contributed equally to this work.

Received 29 January 2008; revised 17 June 2008; accepted 4 July 2008; published online 6 August 2008
In traditional farming systems, farmers maintain a large diversity of species and landraces (Altieri, 1999). Genetic diversity within species plays a major role in lowering the risk of failure and in increasing food security (Teshome et al., 1997; Altieri, 1999; Brush, 2000). However, the evolutionary processes leading to the extent and the pattern of this diversity are still poorly understood (Jarvis and Hodgkin, 1999).

The effects of mating system on the dynamics of genetic diversity may vary in contrasting ecological and demographic conditions and under different farming practices. Gene flow requires not only outcrossing but also the incorporation of new genetic combinations in the population (Slatkin, 1987). In domesticated plants, incorporation of new genetic combinations may involve natural selection and selection exerted by farmers. With an increasing interest in in situ conservation approaches (Brush, 2000), there is a need to study in situ outcrossing rates taking into account the information on biological traits, as well as knowledge about farmers' practices.

Our study was conducted among Duupa farmers in Sub-Sahelian Northern Cameroon. Cultivation of sorghum, Sorghum bicolor ssp. bicolor, is central to Duupa agriculture and society. Duupa agriculture is characterized by a high diversity of crop species as well as by a diversity of landraces of several crops, particularly sorghum (Garine, 1995; Alvarez et al., 2005; Barnaud et al., 2007). With more than 40 sorghum landraces cultivated in the village, belonging to three of the five basic races and to seven of the 10 intermediate forms defined in sorghum taxonomy (Garine, 1995; Barnaud 
et al., 2007), the genetic and morphological diversity of sorghum cultivated by the Duupa is exceptional. A striking feature of Duupa practices is that farmers grow numerous landraces mixed in a field. This should lead to extensive pollen flow between landraces.

In a previous study (Barnaud et al., 2007), we showed that the genetic diversity of 21 landraces is structured in four principal clusters. Two of these clusters present landraces clearly identified by farmers as distinct but not genetically differentiated from one another, suggesting a common genetic background with few genes responsible for the morphological differences perceived by farmers. In contrast, each of the two other clusters is composed of landraces genetically distinct from one another. The significant differentiation we found among clusters and among landraces $\left(F_{\mathrm{st}}=0.35\right.$ in average) suggests the existence of biological barriers to gene flow. The objective of our study was thus to understand whether differences in mating system among landraces might explain the observed pattern of genetic diversity. Our study system provided a good opportunity to evaluate the extent of pollen flow, its links with farming practices, and its impact on the dynamics of diversity in sorghum landrace populations.

Sorghum, Sorghum bicolor ssp. bicolor (L.) Moench, is a main crop throughout semi-arid regions of Africa and Asia. On the basis of seed, spikelet and panicle morphology, Harlan and de Wet (1972) defined five basic races (bicolor, caudatum, durra, guinea and kafir) and 10 intermediate forms in subspecies bicolor. Sorghum flowers are hermaphroditic and wind pollinated.

Sorghum is predominantly selfing (Doggett, 1988; Chantereau and Nicou, 1991). Previous studies, conducted under experimentally controlled conditions, have shown that outcrossing rate $\left(t_{\mathrm{m}}\right)$ varied from 1 to $30 \%$ (Fayed et al., 1976; Ellstrand and Foster, 1983; Chantereau and Kondombo, 1991; Ollitrault et al., 1997; Pedersen et al., 1998). Djè et al. (2004) calculated outcrossing rate in situ in two farmers' fields in Morocco, estimating an outcrossing rate two times as high in one field (landraces of durra-bicolor intermediate type, $t_{\mathrm{m}}=16 \%$ ) as in the other (durra landraces, $t_{\mathrm{m}}=7 \%$ ). They explained these differences by the greater compactness of panicles (restricting pollen movement by wind) in the varieties grown in the latter field.

Although these results are informative, previously reported estimations, both in situ and ex situ, have given only limited information about the variability of outcrossing rate within and among landraces or morphotypes. Estimates of the degree of variability of outcrossing rate within a sorghum population that includes an exceptionally wide range of morphological and racial diversity could provide much more information, which should be valuable for the design of adequate programs for breeding and for the conservation of genetic resources. Along with outcrossing estimates, another important aspect of mating systems is the extent to which biparental inbreeding contributes to genetic structure. Estimates of the degree of relatedness between paternal and maternal parents are often missing in studies of mating systems in plants.

In this study, we estimated parameters of the mating system of five landraces of sorghum representative of the great genetic diversity cultivated by the Duupa. We specifically analyzed (i) the outcrossing rate within and among landraces and parameters of correlated mating; (ii) the relationship between the outcrossing rate and biological traits of the landraces; and (iii) the impact of farmers' practices on pollen flow.

\section{Materials and methods}

\section{Study area}

The village of Wante $\left(8^{\circ} 27^{\prime} \mathrm{N}, 13^{\circ} 18^{\prime} \mathrm{E}\right)$ is close to the unpaved road linking Poli ( $10 \mathrm{~km}$ west of Wanté) to Garoua. Wanté covers $10 \mathrm{~km}^{2}$, where approximately 20 families share lands. Anthropological study of Duupa farming practices has been conducted for over 15 years (Garine, 1995; Garine et al., 2003). Duupa agriculture begins with the sowing period in April-May, corresponding to the beginning of the rainy season. Sorghum is harvested in December-January and threshed in February-March (Garine et al., 2003). Each year farmers select seeds for sowing their next crop. Farmers grow different sorghum landraces mixed in the same fields (eleven on average). Seeds of different landraces are mixed in a common bowl and sown randomly across the field. Landrace names given here are in the Duupa language and written in italics. Duupa phonemes include the glottal stop, transcribed here as an apostrophe.

\section{Plant material}

Plant material was collected in one field. Five landraces were chosen to represent the diversity of sorghum cultivated in the village of Wanté. We chose one landrace from each of the four main clusters identified in a previous study (Barnaud et al., 2007), except for one cluster, from which two landraces were sampled. This cluster in fact included just two landraces, see gooriya and yatta, that were highly differentiated not only from other landraces, but also from each other, with an $F_{\text {st }}$ of 0.59 between them (A Barnaud, unpublished data). Plants of the landrace see gooriya are suspected to be cleistogamous (J Chantereau and E Garine, personal communications). In addition to see gooriya and yatta, the other three landraces sampled were baa dangkaliya, kubaze kolla and $z a^{\prime}$ toota. According to the classification of Harlan and Dewet (1972) those five landraces respectively belong to the following races and intermediate forms: durrabicolor, durra-caudatum, guinea-caudatum, guinea and durra. Detailed characteristics of each landrace are presented in Table 1.

Five panicles per landrace (each panicle from a different plant) were harvested in a single farmer's field in December 2005 when plants were mature. All plants selected were considered by our informants to correspond well to the ideotype of the landrace in question. In this field, 15 landraces were cultivated mixed together. We also found weedy forms around and in the field. The landrace composition of this field can be considered as representative of that resulting from usual Duupa planting practices. The same sets of landraces are usually abundant in most fields, with fields varying in the composition of the less common landraces. For each panicle harvested we measured plant length in metres and panicle length in centimetres, and recorded panicle shape (encoded as 3-very loose drooping primary branches, 5-loose drooping primary branches, 
Table 1 Characteristics of the Duupa landraces used in this study

\begin{tabular}{|c|c|c|c|c|c|c|c|}
\hline Landraces' name & Races & Density & Frequency & Panicle shape & Panicle length & Plant size & Total number of alleles ${ }^{\mathrm{d}}$ \\
\hline baa dangkaliya & guinea caudatum & 3 & 66 & 5 & $4.64 \pm 0.62$ & $30.60 \pm 2.42$ & 13 \\
\hline kubaze kolla & guinea & 40 & 100 & 5 & $4.60 \pm 0.43$ & $35.70 \pm 9.04$ & 19 \\
\hline see gooriya & durra bicolor & 0.5 & 48 & 3 & $3.86 \pm 0.41$ & $31.30 \pm 3.31$ & 18 \\
\hline yatta & durra caudatum & 0.6 & 38 & 3 & $3.50 \pm 0.36$ & $17.50 \pm 1.34$ & 23 \\
\hline$z a^{\prime}$ toota & durra & 0.7 & 59 & 6 & $3.73 \pm 0.57$ & $21.06 \pm 1.10$ & 28 \\
\hline
\end{tabular}

Means are given \pm s.d. in centimetre for panicle length and in metre for plant size.

${ }^{a}$ Density $=$ percentage of panicles encountered per landrace, in transects in 19 fields (taking into account only fields in which the landrace was present).

${ }^{b}$ Frequency $=$ percentage of fields in which a given landrace was cultivated (of 19 fields) according to Barnaud et al. (2007).

cPanicle shape is encoded as 3-very loose drooping primary branches, 5-loose drooping primary branches, 6-semi-loose erect primary branches, following IBPGR/ICRISAT (1993).

d Total number of alleles for each landrace and at the six loci analysed.

6- semi-loose erect primary branches) and the extent to which each grain was covered by the glumes (encoded as $1-<25,2-<50,3-<75 \%$, 4-grain fully covered, 5 - glumes fully open) using descriptors for sorghum developed by IBPGR/ICRISAT (1993; see the website given in that reference for illustrations of panicle diversity and its description).

\section{DNA extraction}

Total genomic DNA was extracted from 1050 seeds, representing 42 seeds per panicle (21 sampled from the apical part of the panicle and 21 from the basal part). In the remaining text, the progeny from a single panicle is called a family. Seeds were germinated and seedlings grown at $23^{\circ} \mathrm{C}$ for 2 weeks. Genomic DNA was extracted from young leaves and roots by using the modified CTAB extraction procedure (Doyle and Doyle, 1990): $500 \mu \mathrm{l}$ of lysis buffer at $65^{\circ} \mathrm{C}(100 \mathrm{mM}$ Tris pH $8.0 ; 1.4 \mathrm{M}$ $\mathrm{NaCl} ; 20$ mM EDTA pH 8.0; $2 \%$ CTAB). After incubation at $65{ }^{\circ} \mathrm{C}$ for $30 \mathrm{~min}, 200 \mu \mathrm{l}$ of chloroform/isoamyl alcohol (24:1) was added. Then, the mix was spun (6000 r.p.m. for $15 \mathrm{~min}$ at $20^{\circ} \mathrm{C}$ ), and the upper phase was precipitated with $1 / 10$ volume of isopropanol at $-20^{\circ} \mathrm{C}$. After an incubation $\left(-20^{\circ} \mathrm{C}\right.$ for $20 \mathrm{~min}$ ) and a spin (6000 r.p.m. for $15 \mathrm{~min}$ ), the supernatant was discarded. The DNA pellet was then washed with $300 \mu \mathrm{l}$ of $70 \%$ ethanol, spun at 6000 r.p.m. for $2 \mathrm{~min}$ and the supernatant was discarded. Finally, after incubation $\left(37^{\circ} \mathrm{C}\right.$ for $\left.2 \mathrm{~h}\right)$, the DNA was dissolved in $100 \mu \mathrm{l}$ of elution buffer AE (Qiagen Inc.).

\section{SSR analyses}

Six mapped microsatellite loci distributed over six of the 10 linkage groups (Kim et al., 2005) were assayed on the 1050 plants. In a previous study, diversity of sorghum landraces was investigated with 14 microsatellite loci (Barnaud et al., 2007). Among these, six loci were chosen for their high polymorphism and for the ease with which results could be unambiguously read and scored: gpsb123 and gpsb151 (developed at CIRAD through the construction of an SSR-enriched gDNA library (Genoplante project)), sb5-236 (Brown et al., 1996), xcup02 (Schloss et al., 2002), xtxp15 (Kong et al., 2000), xtxp289 (Bhattramakki et al., 2000). Plants were genotyped at the IFR 'Biodiversité méditerranéenne et tropicale' platform located on the Montpellier II University campus in France. The forward primer from each microsatellite was 5'-labelled with one of four fluorophores (6-FAM, HEX, VIC and NED). Microsatellite loci with the same fluorophore and with no signal inhibition of PCR products were pooled for PCR. The Multiplex PCR Kit (Qiagen Inc.) was used following the recommended protocol in a final reaction volume of $10: 5 \mu \mathrm{l}$ of $2 \times$ Qiagen Multiplex Master Mix, $2 \mu \mathrm{l}$ of primer mix $(2 \mu \mathrm{M}), 1 \mu \mathrm{l}$ of $\mathrm{H}_{2} \mathrm{O}$ and $2 \mu \mathrm{l}$ of template DNA (30 ng). PCR conditions were: $15 \mathrm{~min}$ of initial denaturation at $95^{\circ} \mathrm{C}$, 35 cycles of $30 \mathrm{~s}$ of denaturation at $94{ }^{\circ} \mathrm{C}, 90 \mathrm{~s}$ of annealing at $57^{\circ} \mathrm{C}, 90 \mathrm{~s}$ of extension at $72^{\circ} \mathrm{C}$ and $10 \mathrm{~min}$ of final elongation at $72{ }^{\circ} \mathrm{C}$. PCR products from different loci were all pooled. $1 \mu \mathrm{l}$ of diluted $(1 / 80)$ PCR products were combined with $0.2 \mu \mathrm{l}$ of the GS500LIZ size standard (Applied Biosystems) and $15 \mu \mathrm{l}$ of deionized formamide. Samples were genotyped on an ABI 3100 Prism (Applied Biosystems, Foster City, USA) using ABI Prism Genemapper (software 3.0 Applied Biosystems). We performed double reading, and carefully checked for the occurrence of null alleles.

\section{Estimation of outcrossing rate}

The multilocus outcrossing rate $\left(t_{\mathrm{m}}\right)$ and the average single-locus outcrossing rate $\left(t_{\mathrm{s}}\right)$ were estimated using the procedure of Ritland (1986) implemented in MLTR software 3.0 (Ritland, 2002). Calculations are based on a mixed mating model assuming selfing rate of $s$ and outcrossing rate of $1-s$. The mixed mating model is based upon the following assumptions: independent segregation of alleles at the different marker loci; no selection or mutation between fertilization and progeny assay and homogeneity of the pollen pool composition over maternal genotype (that is, random mating for outcrosses). The maximum likelihood procedure of MLTR is an iterative two-step process. First, the most likely maternal genotype of each family is inferred; second, the outcrossing rate is estimated from the deviation of progeny arrays from the maternal genotype. From the two algorithms available in MLTR software, namely Newton-Raphson and Expectation Maximisation, we chose to use the Newton-Raphson algorithm, which is faster and allows estimates of negative values (Ritland, 1986). Estimations of confidence intervals for outcrossing rates were obtained using 1000 bootstraps by resampling progenies among families. Pollen and ovule frequencies were jointly estimated with the outcrossing rate. If mating occurs between relatives (biparental inbreeding) some outcrossing events would be confounded with selfing events. The difference between multi- and single-locus outcrossing rates provides an 
estimate of the minimal fraction of apparent selfing events because of biparental inbreeding. MLTR also generates parameters of correlated mating such as the correlation of paternity $\left(r_{\mathrm{p}}\right)$ and the correlation of selfing $\left(r_{\mathrm{s}}\right)$. The first parameter represents the proportion of full sibs in the outcrossed seeds (Ritland, 1989). If an individual plant has $n$ neighbour plants, if each one has the same probability to give pollen and if matings are independent, the number of pollen donors can be estimated using the formula: $r_{\mathrm{p}}=1 / n$, where $n$ is the number of pollen donors (Ritland, 1989). The second parameter, correlation of selfing, is the correlation parameter between two sibs. For example, if $r_{\mathrm{s}}$ is equal to 1 then a pair of sibs are either both selfed or both outcrossed.

Statistical analyses (tests and correlations) were performed using SAS (SAS Institute, 2001) or StatBox 6.6 (2002) and we used an experiment-wise type II error rate of $5 \%$.

\section{Results}

The multilocus outcrossing rate $\left(t_{\mathrm{m}}\right)$ calculated from all progenies was $18 \%( \pm 4 \%)$ and ranged from 0 to $73 \%$ among families (Table 2). Outcrossing rates varied greatly among landraces from $5 \%( \pm 3 \%)$ for the landrace see gooriya to $40 \%( \pm 12 \%)$ for za'toota. Baa dangkaliya, kubaze kolla and yatta had intermediate outcrossing rates of $7 \%( \pm 3 \%), 16 \%( \pm 5 \%)$ and $20 \%( \pm 6 \%)$, respectively (Table 2). Outcrossing rate varied greatly among families within landraces, except for see gooriya (from 3 to $8 \%$ ) and baa dangkaliya (from 0 to $15 \%$ ). This variation was especially marked in the landrace $z a^{\prime}$ toot $a$, where outcrossing rate varied from 12 to $73 \%$ among families. The average single-locus outcrossing rate $\left(t_{\mathrm{s}}\right)$ was $14 \%( \pm 3 \%)$ and ranged from 0 to $49 \%$. Values of $t_{\mathrm{m}}$ and $t_{\mathrm{s}}$ differed significantly from each other (Wilcoxon test, $P<0.01$ ), these differences ranging from 0 to $7 \%$ with a global mean difference of $4 \%$. This test excluded the extreme value given by a single panicle of one landrace for which the difference was even higher $(24 \%)$.

Allelic frequencies were significantly different between pollen and ovule pools (paired $t$-test, $t=6.40$, $P<0.0001$ ) for the six loci analyzed (see Supplementary Information 1). Such differences could be because of pollination from landraces present in the field other than those analyzed. As the maternal multilocus genotypes (see Supplementary Information 2) were similar within a landrace, it is unlikely that differences between pollen and ovule frequencies were because of an unrepresentative sample of maternal plants for each landrace.

Outcrossing rates calculated independently on progeny from the distal and basal parts of the panicles were not significantly different (Wilcoxon test, $P=0.29$ ). Furthermore, when values differed, the direction of the difference was not constant (Table 3). Our analyses are at variance with the results of Maunder and Sharp (1963), who showed variation in outcrossing rate depending on the location of seeds on the panicle, with the distal part of the panicle, where flowering initiates, showing higher outcrossing rate than the basal part.

The correlation of selfing $\left(r_{\mathrm{s}}\right)$ varied among landraces from 0.08 for baa dangkaliya and see gooriya to 0.21 for $z a^{\prime}$ toota. Very low values of the correlation of paternity $r_{\mathrm{p}}$ were found in all landraces except for $z a^{\prime}$ toota, suggesting that with the exception of this last landrace less than $12 \%$ of outcrossed sibs were full sibs (Table 3). Direct observation of the genotypes of outcrossed sibs showed that outcrossed progenies exhibited several non-maternal alleles within a family (data not shown). These observations corroborate the low values of $r_{p}$ in suggesting multiple paternities of the seeds in each panicle. For the overall sample, the estimated number of fathers per panicle (36-42 seeds analyzed per family, except for one family with 26 seeds) varied from eight to ten except for $z a^{\prime}$ toota (three) and the estimated parental inbreeding coefficient $(F)$ was $0.88( \pm 0.04)$. Using the classical formula $t=(1-F) /(1+F)$ leads to an indirect estimation of the outcrossing rate of $6.3 \%$. The high value of $F$ indicates that the parental (maternal) generation was produced largely by inbred matings. A further indication of this is that a large number of mothers (18 of 25) were homozygous at all loci.

We then investigated the correlation between multilocus outcrossing rate of a given progeny and morphological characteristics of the maternal plant. A significant negative correlation was found between $t_{\mathrm{m}}$ and plant height (Pearson's correlation $r=-0.41, P=0.04$ ). Smaller plants had more outcrossed progeny than did taller plants, the smallest plants receiving the most pollen from other individuals. We also showed a significant effect of identity of the landrace on plant size (one-way ANOVA, $P=0.009$ ). To investigate the effect of landrace on $t_{\mathrm{m}}$, we therefore conducted a two-way ANOVA with plant size as a co-factor. This analysis showed that the effect of the factor 'landrace' was significant $(P<0.005)$. Effect of the factor 'plant size' and the interaction were not significant. Therefore, variation in plant size alone cannot explain the significant effect of landraces on $t_{\mathrm{m}}$.

\section{Discussion}

\section{Estimates of outcrossing rate}

Our estimates of outcrossing rate confirmed that cultivated sorghum exhibits a mixed mating system, with predominant selfing. We found an average outcrossing rate of $18 \%$, which lies within the range of outcrossing rates previously reported for sorghum both in experimental conditions (from 0\% (Pedersen et al., 1998) to 30\% (Ellstrand and Foster, 1983)) and in situ (from 7 to 16\% Djè et al. (2004)). Outcrossing rate showed great variability within and among landraces. We have shown here that outcrossing rates in domesticated sorghum may be as high as 73\% for a particular family. To our knowledge, values this high have never been shown in domesticated sorghum. Pedersen et al. (1998) showed a similar range of variation, from 0 to $100 \%$, in sudangrass, S. bicolor subsp. drummondii (see also Garber and Atwood, 1945).

It has been shown that deviation from the model assumption of random mating for outcrosses can affect the precision of outcrossing rate estimates (Ennos and Clegg, 1982). Our low values of $r_{\mathrm{p}}$ for almost all landraces (except for $z a^{\prime}$ toota) allow us to reject the hypothesis of non-random mating among the outcrossed progenies. Furthermore, we observed a low biparental inbreeding coefficient $(4 \%)$, which fits with usual values calculated for plant populations: mean $t_{\mathrm{m}}-t_{\mathrm{s}}=3.4 \%$ (Jarne and Auld, 2006, using the plant data set from Goodwillie et al. (2005)). The low value of the biparental 
Table 2 Estimates of multilocus outcrossing rate $\left(t_{m}\right)$ and the average single-locus outcrossing rate $\left(t_{s}\right)$ among progeny families

\begin{tabular}{|c|c|c|c|c|c|c|c|c|}
\hline Landrace & Race & Family (no of individuals) & $\mathrm{t}_{m}$ & s.d. ${ }^{a}$ & $\mathbf{t}_{s}$ & s.d. & $t_{m}-t_{s}^{b}$ & s.d. \\
\hline & & $1(40)$ & 0.15 & 0.07 & 0.10 & 0.05 & 0.05 & 0.03 \\
\hline & & $2(38)$ & 0.02 & 0.01 & 0.01 & 0.00 & 0.01 & 0.01 \\
\hline \multirow[t]{3}{*}{ baa dangkaliya } & guinea-caudatum & $3(40)$ & 0.07 & 0.04 & 0.03 & 0.01 & 0.05 & 0.02 \\
\hline & & $4(41)$ & 0.00 & 0.00 & 0.00 & 0.00 & 0.00 & 0.00 \\
\hline & & $5(37)$ & 0.08 & 0.04 & 0.03 & 0.01 & 0.05 & 0.03 \\
\hline \multirow[t]{3}{*}{ Estimated mean for the landrace } & & & 0.07 & 0.03 & 0.03 & 0.02 & 0.04 & 0.01 \\
\hline & & $1(42)$ & 0.10 & 0.05 & 0.07 & 0.03 & 0.03 & 0.01 \\
\hline & & $2(39)$ & 0.15 & 0.05 & 0.09 & 0.05 & 0.06 & 0.03 \\
\hline \multirow[t]{3}{*}{ kubaze kolla } & guinea & $3(42)$ & 0.27 & 0.05 & 0.20 & 0.10 & 0.07 & 0.03 \\
\hline & & $4(40)$ & 0.00 & 0.00 & 0.00 & 0.00 & 0.00 & 0.00 \\
\hline & & $5(41)$ & 0.28 & 0.05 & 0.24 & 0.12 & 0.04 & 0.02 \\
\hline \multirow[t]{3}{*}{ Estimated mean for the landrace } & & & 0.16 & 0.05 & 0.13 & 0.04 & 0.03 & 0.02 \\
\hline & & $1(42)$ & 0.05 & 0.04 & 0.03 & 0.01 & 0.02 & 0.04 \\
\hline & & $2(38)$ & 0.05 & 0.03 & 0.01 & 0.01 & 0.04 & 0.02 \\
\hline \multirow[t]{3}{*}{ see gooriya } & durra-bicolor & $3(41)$ & 0.03 & 0.02 & 0.01 & 0.00 & 0.02 & 0.02 \\
\hline & & $4(39)$ & 0.08 & 0.04 & 0.05 & 0.02 & 0.03 & 0.01 \\
\hline & & $5(26)$ & 0.04 & 0.02 & 0.02 & 0.01 & 0.02 & 0.01 \\
\hline \multirow[t]{3}{*}{ Estimated mean for the landrace } & & & 0.05 & 0.03 & 0.02 & 0.01 & 0.03 & 0.03 \\
\hline & & $1(41)$ & 0.02 & 0.01 & 0.02 & 0.01 & 0.00 & 0.00 \\
\hline & & $2(42)$ & 0.36 & 0.17 & 0.29 & 0.14 & 0.07 & 0.03 \\
\hline \multirow[t]{3}{*}{ yatta } & durra-caudatum & $3(36)$ & 0.31 & 0.15 & 0.24 & 0.11 & 0.07 & 0.03 \\
\hline & & $4(42)$ & 0.17 & 0.08 & 0.12 & 0.06 & 0.05 & 0.02 \\
\hline & & $5(42)$ & 0.17 & 0.08 & 0.12 & 0.06 & 0.05 & 0.02 \\
\hline \multirow[t]{3}{*}{ Estimated mean for the landrace } & & & 0.20 & 0.06 & 0.14 & 0.05 & 0.06 & 0.02 \\
\hline & & $1(41)$ & 0.73 & 0.35 & 0.49 & 0.24 & 0.24 & 0.11 \\
\hline & & $2(38)$ & 0.42 & 0.20 & 0.37 & 0.18 & 0.05 & 0.03 \\
\hline \multirow[t]{3}{*}{$z a^{\prime}$ toota } & durra & $3(41)$ & 0.49 & 0.23 & 0.47 & 0.23 & 0.02 & 0.03 \\
\hline & & $4(42)$ & 0.12 & 0.06 & 0.09 & 0.04 & 0.03 & 0.02 \\
\hline & & $5(40)$ & 0.23 & 0.13 & 0.22 & 0.11 & 0.01 & 0.07 \\
\hline Estimated mean for the landrace & & & 0.40 & 0.12 & 0.33 & 0.08 & 0.07 & 0.08 \\
\hline Global estimated means & & & 0.18 & 0.04 & 0.14 & 0.03 & 0.04 & 0.01 \\
\hline
\end{tabular}

a Standard deviation obtained from 1000 bootstraps.

${ }^{\mathrm{b}}$ Minimal fraction of apparent selfing events because of biparental inbreeding.

Table 3 Estimated multilocus outcrossing rates $\left(t_{m}\right)$ of landraces based on progeny from the distal (D) and basal (B) parts of panicles

\begin{tabular}{llllllllll}
\hline Landraces & Race & $\mathrm{t}_{m} D$ & s.d. & $\mathrm{t}_{m} B$ & s.d. & $\mathrm{r}_{s}$ & s.d. & $\mathrm{r}_{p}$ & s.d. \\
\hline baa dangkaliya & $\mathrm{GC}$ & 0.05 & 0.03 & 0.08 & 0.03 & 0.08 & 0.04 & 0.11 & 0.02 \\
kubaze kolla & $\mathrm{G}$ & 0.17 & 0.06 & 0.16 & 0.06 & 0.11 & 0.11 & 0.12 & 0.03 \\
see gooriya & $\mathrm{DB}$ & 0.04 & 0.02 & 0.05 & 0.15 & 0.08 & 0.02 & 0.10 & 0.01 \\
yatta & $\mathrm{DC}$ & 0.13 & 0.22 & 0.27 & 0.19 & 0.09 & 0.09 & 0.11 & 0.01 \\
za'toota & $\mathrm{D}$ & 0.51 & 0.14 & 0.56 & 0.07 & 0.21 & 0.12 & 0.32 & 0.07
\end{tabular}

Parameters estimating correlated mating (correlation of selfing $\left(r_{\mathrm{s}}\right)$ and correlation of paternity $\left.\left(r_{\mathrm{p}}\right)\right)$ are also given. Each value is given with its s.d., obtained from 1000 bootstraps.

inbreeding coefficient suggests that we can differentiate between self-fertilization and mating between relatives. Although s.d. for estimates of $t_{\mathrm{m}}$ were high, this appears to reflect real variability rather than undersampling, as we analyzed from 36 to 42 seeds per family (except for one family with 26 seeds) and as there was a significant effect of landrace on $t_{\mathrm{m}}$.

Outcrossing rates are influenced not only by maternal genotype but also by environmental conditions. AbdelGhani et al. (2004) showed that outcrossing rate varied greatly among seasons in populations of barley landraces and in wild populations. In our study, sorghum landraces varied greatly in their mating system within a single year, in which all plants experienced similar environmental conditions. The extent to which phenotypic plasticity introduces further variation is unknown.
Biological traits and variation in outcrossing rate Inflorescence morphology, characterized by the shape of the panicle, can also have an impact on the outcrossing rate and thus on the structure of genetic diversity. Chantereau and Kondombo (1991) suggested that loose panicles, such as those of guinea landraces, favour outcrossing, whereas the architecture of very compact panicles, such as those typical of durra landraces, impedes outcrossing (see also Djè et al., 2004). In our study, the guinea landrace kubaze kolla appears to exemplify this proposed trend. With an outcrossing rate averaging $16 \%$ (0-28\% among families), kubaze kolla is on the high end of the range of variation, and its outcrossing rate is similar to those observed in previous studies of guinea landraces (Chantereau and Kondombo, 1991; Ollitrault et al., 1997). However, $z a^{\prime}$ toota, a durra landrace, presents even higher outcrossing rates, whereas lower values would be expected for durra landraces based on inflorescence morphology (Fayed et al., 1976; Djè et al., 2004). The panicle of $z a^{\prime}$ toota is, however, looser than those of most durra landraces (Table 1). Cytoplasmic male sterility, which has been demonstrated in guineacaudatum, caudatum, durra and guinea races (Rooney, 2000, using the data from Schertz (1983)) may also explain the high outcrossing rates found for a panicle of $z a^{\prime}$ toota $\left(t_{\mathrm{m}}=73 \pm 35 \%\right)$.

Differences in floral traits can also have an impact on outcrossing. Cleistogamy (flowers remain enclosed) strongly reduces pollen flow. Owing to their very long glumes, which prevent pollen movement, flowers of the 
landrace see gooriya are effectively cleistogamous, in contrast to all other Duupa sorghum landraces, which may be characterized as chasmogamous. Cleistogamy may be the principal explanation for the low outcrossing rate (5\% on average) and the low variation in outcrossing rates among families that characterize this landrace. By imposing a partial barrier to pollen flow, floral morphology contributes to genetic differentiation of the landrace see gooriya.

In addition to inflorescence morphology and floral traits, phenology can also influence pollen flow. However, flowering phenology did not constitute a biological barrier to pollen exchange in our study. A field trial conducted on 19 sorghum landraces cultivated in the village of Wanté (including the 15 landraces studied here) showed that landraces have overlapping flowering times (data not shown).

\section{Impact of the spatial structure of mixed-landrace fields on pollen flow}

A striking feature of Duupa cultivation is that farmers grow different sorghum landraces mixed in the same field. They appear not to have a spatial strategy that would limit pollen flow among landraces. The importance of spatial distribution of genetically differentiated landraces in influencing mating system in sorghum was shown by Ellstrand and Foster (1983), who showed that population structure had a great impact on the apparent outcrossing rate, a stratified treatment (varieties in rows over the field) producing significantly lower outcrossing rates than an overdispersed treatment (varieties mixed in the field). Schmidt and Bothma (2006) showed that pollen flow in sorghum in experimental conditions was relatively high within the first $40 \mathrm{~m}$ and continued to be observable at low levels at distances up to $158 \mathrm{~m}$. Two features of the spatial distribution of landraces at Wanté- the pattern of planting fields with mixed landraces, and the close proximity of fields with different collections of landraces-favour pollen flow. Little information exists for comparing these patterns with those in other traditional sorghum cultivation systems. In Ethiopia, Teshome et al. (1999) showed an average of 9.75 landraces per field (from 1 to 24 landraces) in transects in 260 sorghum fields. However, that study was exceptional, because most studies do not provide clear data on the spatial patterns of cultivation of different landraces.

Together with outcrossing rate, the pattern of correlated mating is a key parameter of the mating system (Ritland, 1989). To our knowledge, no studies of mating systems in sorghum report any estimates of correlation of paternity. Our results indicate that the outcrossed seeds of a given family were pollinated by several parents (usually by more than eight pollen donors except for $z a^{\prime}$ toota). These patterns are expected for wind-pollinated plants with overlapping flowering periods. In contrast, in $z a^{\prime}$ toota, which presented the highest outcrossing rate $\left(t_{\mathrm{m}}=40 \%\right)$, the correlation of paternity was relatively high and suggested that only up to three fathers contributed the pollen for seeds of a given panicle. In plant populations, two types of mechanisms causing correlated paternity can be distinguished: (i) nonindependent dispersal events (co-dispersal of pollen from the same origin) and (ii) limited mate availability (low number of pollen donors) (Hardy et al., 2004). It seems to us that co-dispersal of pollen is unlikely to occur in sorghum pollination; indeed the cultivated form is reported to be wind-pollinated and pollen in Poaceae is not aggregated. On the other hand, studies on pearl millet have shown that pollen competition could favour pollen from the same variety as the maternal plant (Robert et al., 1992). A similar phenomenon could explain why $z a^{\prime}$ toota, a durra landrace, exhibited a high correlated paternity. This landrace is present at low density in fields. Most potential pollen donors belong to other races or forms (guinea or guinea-caudatum) and their pollen is perhaps less competitive than that of $z a^{\prime}$ toota on maternal plants of the latter landrace. In a previous study, we showed that $z a^{\prime}$ toota is genetically distinct from other landraces in the same cluster (in contrast to the cluster of guinea landraces, which are not differentiated from one another). Pollen competition might explain in part the maintenance of genetic differentiation between these related landraces.

The Duupa farmers not only planted landraces mixed in fields, they also varied the abundance of different landraces, with some, such as kubaze kolla (40\% of the harvest), typically abundantly planted in fields and others in very low abundance (for example, yatta, less than $1 \%$ of the harvest) (Table 1). A survey of the distribution of the landraces cultivated in the village of Wanté showed that landraces representing the largest part of the harvest are all guinea or guinea-caudatum landraces (Barnaud et al., 2007). These differences in density of landraces might promote pollen flow from guinea landraces to the less abundant landraces of other races, which showed in our study higher outcrossing rates. Papa and Gepts (2003) demonstrated such a pattern in common bean (Phaseolus vulgaris), where gene flow from domesticated to wild was found to be 3-4 times higher than in the opposite direction in part because of the difference in the sizes of the respective populations.

Finally, although the planting practices of Duupa farmers and the biological traits of sorghum lead to extensive pollen flow among landraces, the ultimate survival and maintenance of new genetic combinations from outcrossing events depend on the fitness of outcrossed seeds. For cultivated plants, incorporation of new genetic combinations involves natural selection and selection exerted by farmers. Concerning natural selection, plants compete in fields and this competition might lead to more mortality when the field is young and plants are small. Belhaj Fraj et al. (2003) showed that competitive mechanisms occurred in wheat cultivar mixtures; four cultivars, sown in equal proportions, varied from 15 to $37 \%$ at harvest. Mating system and inbreeding depression are inextricably linked. Theory suggests that the main factor opposing the evolution of selfing is inbreeding depression. However, mainly selfing populations, such as those of sorghum, should be little affected by inbreeding depression, being purged of deleterious alleles. Thus, there is no reason to think that in sorghum selfed seeds will be less fit than outcrossed seeds. It is noteworthy that 18 of 25 maternal parents, chosen for their correspondence to the ideotype of the landrace in question, were homozygous at all loci. Inbred, and hence highly homozygous, plants may more faithfully reproduce the ideotype selected by farmers. 
Impact of farmers' practices on pollen flow

The magnitude and characteristics of pollen flow are highly influenced by farmers' management of their diversity. In Wanté, farmers select panicles for sowing their next crop. The panicles chosen correspond to distinctive ideotypes and farmers always tell us that they choose big panicles whose seeds have open glumes. Furthermore, farmers actively select against plants that are not true to type. All panicles which cannot be attributed to one or another landrace are eliminated from the seed sowing. These types which fall outside landrace ideotypes are called genkiya (Barnaud, 2007). This selection helps to maintain characteristics of landraces despite pollen flow. The estimated value of the parental inbreeding coefficient $(F=0.88)$ gives an indirect estimation of the outcrossing rate of $6.3 \%$. Estimates of outcrossing rates based on progeny arrays were threefold higher than the estimates based on $F$. This discrepancy between the two estimates might be because of selection processes after pollination. Thus, it would be of particular interest to quantify the selection exerted by farmers to understand the factors that allow maintenance of genetic structure. For instance, our results on the outcrossing rate do not allow us to explain how the landrace yatta is maintained.

\section{Consequences for conservation strategies and crop improvement}

In many traditionally managed agroecosystems, domesticated plants present high levels of genetic diversity, as we have documented for sorghum landraces cultivated by Duupa farmers (Barnaud et al., 2007). The fate of this diversity and the threat of erosion are current conservation concerns, motivating studies on how diversity can be maintained by in situ conservation strategies; and more precisely, on how biological traits of plants, such as a mating system, interact with farmers' practices to influence evolutionary forces-drift, migration, selection and mutation-and thereby the dynamics of genetic diversity. In this study, different biological factors explain how sorghum landraces are maintained. Whereas guinea/guinea-caudatum landraces have a common genetic background because of high outcrossing rate, floral traits and pollen competition appear to explain the pattern of genetic diversity for see gooriya and $z a^{\prime}$ toota. However, our study failed to find the factors explaining the maintenance of yatta. Farmers' selection practices, still incompletely understood, appear to be the key to explaining the maintenance of so many distinct landraces. Identifying key processes should facilitate the design of in situ conservation measures to maintain crop diversity against the threat of genetic erosion. Furthermore, the variability of biological traits such as mating systems, and the interaction of this variability with farmers' practices, must be taken into account to model the evolution of domesticated plants.

\section{Acknowledgements}

This work is part of the $\mathrm{PhD}$ thesis of the first author, who was funded by a fellowship from the French Ministry of Research. This research was funded by a grant from the 'Institut Français de la Biodiversité'. We thank Eric Garine for assistance in the anthropological part of the study. Laure Benoît and the IFR 'Biodiversité méditerranéenne et tropicale' platform located on the Montpellier II University campus in France are thanked for technical assistance. Finn Kjellberg gave valuable suggestions on a previous version of the paper. We thank the government of Cameroon for allowing us to carry out our fieldwork in Wanté, and Aboubacar Moussa and the MEADEN (study mission for the development of the North province) for their assistance in Cameroon. Research assistance by Simon Monné and Celestin Khasah is gratefully acknowledged. Our greatest debt of gratitude is to the Duupa farmers of Wanté for providing the research material, for their hospitality and for their interest in participating in our study. We thank two anonymous reviewers and the editor for their valuable suggestions.

\section{References}

Abdel-Ghani AH, Parzies HK, Omary A, Geiger HH (2004). Estimating the outcrossing rate of barley landraces and wild barley populations collected from ecologically different regions of Jordan. Theor Appl Genet 109: 588-595.

Altieri MA (1999). The ecological role of biodiversity in agroecosystems. Agricult Ecosys Environ 74: 19-31.

Alvarez N, Garine E, Khasah C, Dounias E, Hossaert-McKey M, McKey D (2005). Farmers' practices, metapopulation dynamics, and conservation of agricultural biodiversity on-farm: a case study of sorghum among the Duupa in sub-sahelian Cameroon. Biol Conserv 121: 533-543.

Barnaud A (2007). Savoirs, pratiques et dynamique de la diversité génétique : le sorgho (Sorghum bicolor ssp. bicolor) chez les Duupa du nord Cameroun. Thèse de Doctorat, Université Montpellier II. http://www.cefe.cnrs.fr/coev/ Default.htm.

Barnaud A, Deu M, Garine E, McKey D, Joly HI (2007). Local genetic diversity of sorghum in a village in northern Cameroon: structure and dynamics of landraces. Theor Appl Genet 114: 237-248.

Belhaj Fraj M, Falentin-Guyomarc'h H, Monod H, VallavieillePope C (2003). The use of microsatellite markers to determine the relative proportions of grain produced by cultivars and the frequency of hybridization in bread wheat mixtures. Plant Breeding 122: 385-391.

Bhattramakki D, Dong JM, Chhabra AK, Hart GE (2000). An integrated SSR and RFLP linkage map of Sorghum bicolor (L. Moench). Genome 43: 988-1002.

Brown SM, Hopkins MS, Mitchell SE, Senior ML, Wang TY, Duncan RR et al. (1996). Multiple methods for the identification of polymorphic simple sequence repeats (SSRs) in sorghum [Sorghum bicolor (L.) Moench]. Theor Appl Genet 93: 190-198.

Brush SB (2000). The issue of in situ conservation of crop genetic resources. In: Brush SB (ed). Genes in the Field: On-Farm Conservation of Crop Diversity. IDRC/IPGRI/Lewis Publishers: Boca Raton, USA, pp 3-26.

Chantereau J, Kondombo C (1991). Estimation du taux d'allogamie chez les sorghos de la race guinea. In: Salez $\mathrm{P}$ (ed). Compte rendu de mission à la conférence des réseaux Safgrad. Conférence inter-réseaux sur la recherche et la production des cultures vivrières: Niamey, Niger, 7pp.

Chantereau J, Nicou R (1991). Le sorgho. Maisonneuve \& Larose: Paris.

Djè Y, Heuertz M, Ater M, Lefebvre C, Vekemans X (2004). In situ estimation of outcrossing rate in sorghum landraces using microsatellite markers. Euphytica 138: 205-212.

Doggett H (1988). Sorghum. Longman Scientific: Essex, UK.

Doyle JF, Doyle JL (1990). Isolation of plant DNA from fresh tissue. Focus 12: 13-15. 
Ellstrand NC, Foster KW (1983). Impact of population structure on the apparent outcrossing rate of grain sorghum (Sorghum bicolor). Theor Appl Genet 66: 323-327.

Ennos RA, Clegg MT (1982). Effect of population substructuring on estimates of outcrossing rate in plant populations. Heredity 48: 283-292.

Fayed MFS, Ali AH, Bashir MI (1976). Natural cross-pollination in grain sorghum varieties in A.R.E. AgricHum Values 54: 145-151.

Garber RJ, Atwood SS (1945). Natural crossing in sudangrass. J Am Soc Agron 37: 365-369.

Garine E (1995). Le système agraire des Duupa du Massif de Poli (Nord Cameroun), Thèse de Doctorat, Université Paris X.

Garine E, Khasah C, Raimond C (2003). Battre et vanner son mil: un moment clé de la chaîne opératoire chez les cultivateurs díi et duupa (Nord-Cameroun)?. In: Anderson PC, Cummings LS, Schippers TK, Simonel B (eds). Le traitement des récoltes: un regard sur la diversité, du néolithique au présent. APDCA: Antibes, France, pp 61-85.

Goodwillie C, Kalisz S, Eckert CG (2005). The evolutionary enigma of mixed mating systems in plants: occurrence, theoretical explanations, and empirical evidence. Annu Rev Ecol Evol S 36: 47-79.

Hardy OJ, Gonzalez-Martinez SC, Colas B, Freville H, Mignot A, Olivieri I (2004). Fine-scale genetic structure and gene dispersal in Centaurea corymbosa (Asteraceae). II Correlated paternity within and among sibships. Genetics 168: 1601-1614.

Harlan JR, de Wet JMJ (1972). Simplified classification of cultivated sorghum. Crop Sci 12: 172-176.

IBPGR/ICRISAT (1993). Descriptors for Sorghum [Sorghum bicolor (L) Moench]. International Board of Plant Genetic Resources. Rome, Italy/International Crop Research Institute for Semi-Arid Tropics, Patancheru, India.http://www. bioversityinternational.org/Publications/pubfile.asp?ID_PUB $=251$

Jarne P, Auld JR (2006). Animals mix it up too: the distribution of self-fertilization among hermaphroditic animals. Evolution 60: 1816-1824.

Jarvis DI, Hodgkin T (1999). Wild relatives and crop cultivars: detecting natural introgression and farmer selection of new genetic combinations in agroecosystems. Mol Ecol 8: S159-S173.

Kim J-S, Klein PE, Klein RR, Price HJ, Mullet JE, Stelly DM (2005). Chromosome identification and nomenclature of Sorghum bicolor. Genetics 169: 955-965.

Kong L, Dong J, Hart GE (2000). Characteristics, linkage-map positions, and allelic differentiation of Sorghum bicolor (L.) Moench DNA simple-sequence repeats (SSRs). Theor Appl Genet 101: 438-448.

Leblanc O, Peel MD, Carman JG, Savidan Y (1995). Megasporogenesis and megagametogenesis in several Tripsacum species (Poaceae). Am J Bot 82: 57-63.
Maunder A, Sharp G (1963). Localization of outcrosses within panicle of fertile sorghum. Crop Sci 3: 449.

Ollitrault P, Noyer JL, Chantereau J, Glaszmann JC (1997). Structure génétiques et dynamique des variétés traditionnelles de sorgho au Burkina-Faso. In: Begic A (ed). Gestion des ressources génétiques des plantes en Afrique des savanes. IER-BRG Solagral, Bamako, Mali, pp 231-240.

Papa R, Gepts P (2003). Asymmetry of gene flow and differential geographical structure of molecular diversity in wild and domesticated common bean (Phaseolus vulgaris L.) from Mesoamerica. Theor Appl Genet 106: 239-250.

Pedersen JF, Toy JJ, Johnson B (1998). Natural outcrossing of sorghum and sudangrass in the central great plains. Crop Sci 38: 937-939.

Ritland K (1986). Joint maximum-likelihood-estimation of genetic and mating structure using open-pollinated progenies. Biometrics 42: 25-43.

Ritland K (1989). Correlated matings in the partial selfer Mimulus guttatus. Evolution 43: 848-859.

Ritland K (2002). Extensions of models for the estimation of mating systems using $n$ independent loci. Heredity 88: 221-228.

Robert T, Lamy F, Sarr A (1992). Evolutionary role of gametophytic selection in the domestication of Pennisetum thyphoides (pearl millet): a two-locus asymmetrical model. Heredity 69: 372-381.

Rooney WL (2000). Genetics and cytogenetics. In: Smith CW, Frederiksen, RA (eds). Sorghum: Origin, History Technology, and Production. John Wiley \& Sons: New York. pp 261-307.

Ross-Ibarra J, Morrell PL, Gaut BS (2007). Plant domestication, a unique opportunity to identify the genetic basis of adaptation. Proc Natl Acad Sci 104: 8641-8648.

SAS Institute Inc (2001). SAS OnlineDocs, Version 8.02. SAS Institute Inc: Cary, NC.

Schertz KF (1983). Potentials with new cytoplasmic male sterility systems in sorghum. Proc Genet Soc Am 38: 890-893.

Schloss SJ, Mitchell SE, White GM, Kukatla R, Bowers JE, Paterson AH et al. (2002). Characterization of RFLP probe sequences for gene discovery and SSR development in Sorghum bicolor (L.) Moench. Theor Appl Genet 105: 912-920.

Schmidt M, Bothma G (2006). Risk assessment for transgenic sorghum in Africa: Crop-to-crop gene flow in Sorghum bicolor (L.) Moench. Crop Sci 46: 790-798

Slatkin M (1987). Gene flow and the geographic structure of natural populations. Science 236: 787-792.

Teshome A, Baum BR, Fahrig L, Torrance JK, Arnason TJ, Lambert JD (1997). Sorghum [Sorghum bicolor (L.) Moench] landrace variation and classification in north Shewa and south Welo, Ethiopia. Euphytica 97: 255-263.

Teshome A, Fahrig L, Torrance JK, Lambert JD, Arnason TJ, Baum BR (1999). Maintenance of sorghum (Sorghum bicolor, Poaceae) landrace diversity by farmers' selection in Ethiopia. Econ Bot 53: 79-88.

Supplementary Information accompanies the paper on Heredity website (http://www.nature.com/hdy) 